\title{
Dry metal forming of high alloy steel using laser generated aluminum bronze tools
}

\author{
Hannes Freiße $\mathrm{e}^{1, \mathrm{a}}$, Henry Köhler ${ }^{1}$, Thomas Seefeld ${ }^{1}$, and Frank Vollertsen ${ }^{1,2}$ \\ ${ }^{1}$ BIAS-Bremer Institut für angewandte Strahltechnik GmbH, Klagenfurter Str. 2, 28359 Bremen, \\ Germany \\ ${ }^{2}$ University of Bremen, Bibliothekstraße 1, 28359 Bremen, Germany
}

\begin{abstract}
Regarding the optimization of forming technology in economic and environmental aspects, avoiding lubricants is an approach to realize the vision of a new green technology. The resulting direct contact between the tool and the sheet in non-lubricated deep drawing causes higher stress and depends mainly on the material combination. The tribological system in dry sliding has to be assessed by means on the one hand of the resulting friction coefficient and on the other hand of the wear of the tool and sheet material. The potential to generate tailored tribological systems for dry metal forming could be shown within the investigations by using different material combinations and by applying different laser cladding process parameters. Furthermore, the feasibility of additive manufacturing of a deep drawing tool was demonstrated. The tool was successfully applied to form circular cups in a dry metal forming process.
\end{abstract}

\section{Introduction}

Dry metal forming is a new approach to establish sustainable production technology in metal forming. A new green technology in mass production can be realised by avoiding lubricants. Thereby process steps in production as cleaning, environmental impacts, the demand of oil in production and avoidable health burden could be reduced [1]. Forming metal without lubrication causes a direct contact between the sheet and the tool, which results in intensive mechanical interaction. The challenge is to understand the dry sliding process for a defined material combination and to modify the tool surfaces accordingly. To evaluate the tool in dependence of the sheet material for dry forming, an eligibility number can be applied [2]. Reducing the wear and the friction coefficient is the target for current investigations to integrate dry metal forming in industrial mass production. Dry deep drawing of various sheet metals was investigated for example by controlled selective oxidation of cold work steel surfaces [3], by using ceramic tools [4] or by macro- and microscopically modified surfaces of a deep drawing tool [5]. Comprehensive tribological aspects in dry forming were presented by [6].

Up to now, lubrication is necessary for forming processes in industrial mass production. A proven tool material to form high alloy austenitic steel is aluminum bronze. Relevant areas of the deep

\footnotetext{
${ }^{\text {a }}$ Corresponding author: freisse@bias.de
}

This is an Open Access article distributed under the terms of the Creative Commons Attribution License 4.0, which permits unrestricted use, distribution, and reproduction in any medium, provided the original work is properly cited. 


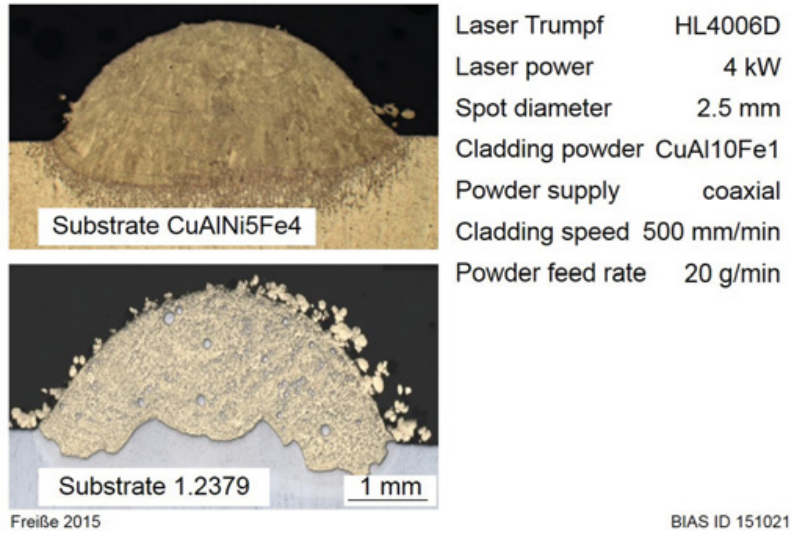

Figure 1. Metallurgical cross section.

drawing tool surface can be modified using aluminum bronze coatings by laser cladding [7]. Laser cladding is a manufacturing technique for modifying surfaces, for repairing applications and for additive manufacturing processes for example of forming tools [8]. In this work an approach for dry metal forming is presented of using laser cladding as a production technology and aluminum bronze as a tool material to generate surfaces and to manufacture a deep drawing tool.

\section{Laser cladding and tribological testing}

Laser cladding experiments were carried out on both aluminum bronze substrate CuAl10Ni5Fe4 and cold work steel substrate 1.2379. A $4 \mathrm{~kW}$ Trumpf HL4006D lamped pump Nd:YAG laser was applied in the experimental set-up. The focused laser radiation and the cladding material were delivered by means of the laser processing head Precitec YC50 to deposit cladding tracks on the substrate. Argon was used as a shielding gas to protect the process zone against oxidation. The cladding material was aluminum bronze $\mathrm{CuAl10Fe} 1$ in form of gas-atomized powder. The powder feed rate amounted to $20 \mathrm{~g} / \mathrm{min}$.

Different parameters of the process were varied to investigate the possibility to modify the properties of the cladded tracks. Therefore, two different powder particles sizes were applied. A fine powder with a particle size from $5 \mu \mathrm{m}$ to $53 \mu \mathrm{m}$ and a coarse powder with a particle size from $45 \mu \mathrm{m}$ to $125 \mu \mathrm{m}$. Four different cladding speeds were used to vary the energy per unit length. Furthermore, the cladded tracks were post-processed by laser remelting.

By means of metallurgical cross sections, all clads were examined for imperfections and the geometry of the tracks was determined. Figure 1 shows a metallurgical cross section. No pores or cracks were detected in the cross sections of all specimen. The height of the tracks depended on the cladding speed. Applying a lower speed of $0.5 \mathrm{~m} / \mathrm{min}$ led to a height of $1.36 \mathrm{~mm}$ and a higher cladding speed of $2 \mathrm{~m} / \mathrm{min}$ led to a height of $0.37 \mathrm{~mm}$. However, variation of the process speed did not particularly impact on the width. The width was approximately $3.8 \mathrm{~mm}$ with a standard deviation of $0.4 \mathrm{~mm}$.

All specimens were tested in a dry oscillating ball-on-plate test to determine the tribological behaviour for dry forming. The counter body was the high alloy austenitic steel 1.4301 with a hardness of $242 \mathrm{HV} 0.5$. This steel represented the sheet material in forming processes. The test duration was $24 \mathrm{~h}$. By applying a normal force of $10 \mathrm{~N}$ the maximum Hertzian pressure at the beginning of the test amounted to $807 \mathrm{MPa}$. At the end of the test the calotte was worn out and the surface pressure was 3.7 MPa.

Reference tests were carried out by dry oscillating ball-on-plate tests directly both on the cold work steel and on the aluminum bronze substrate. Within dry sliding on aluminum bronze substrate, the 


\section{ICNFT 2015}
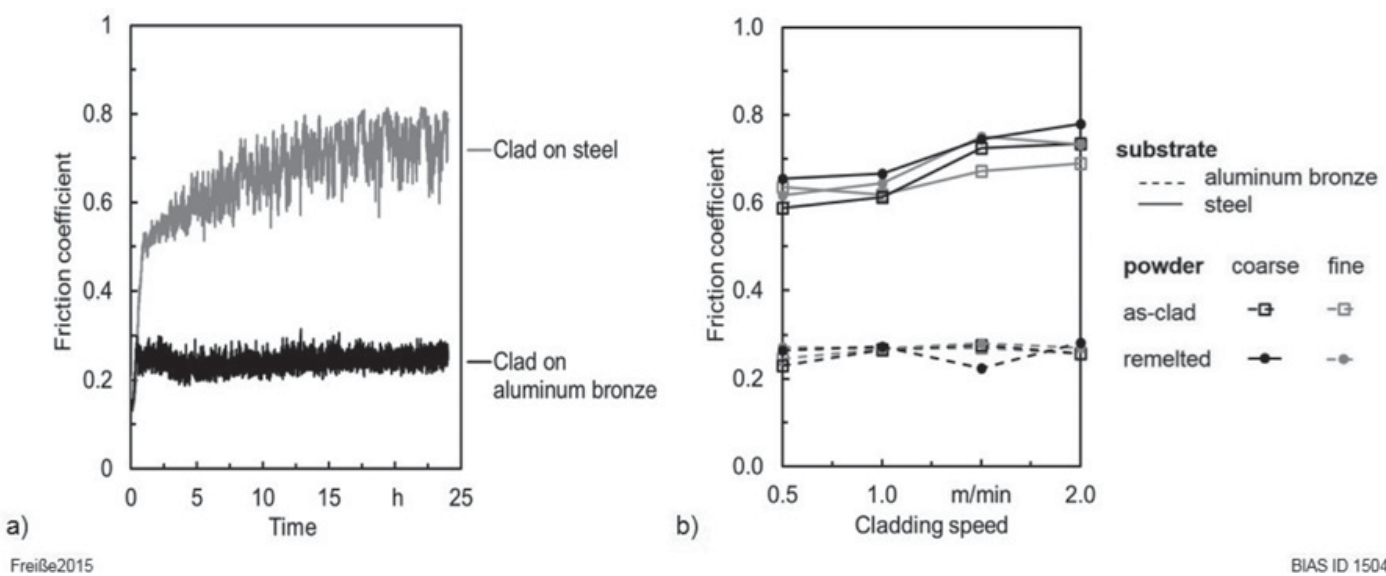

BIAS ID 150400

Figure 2. Results of friction coefficient. a) Exemplary transient measurement data and b) average friction coefficient for the modified surfaces.

average friction coefficient of three measurements was 0.38 with a standard deviation of 0.005 . The test on the steel revealed a higher friction coefficient of 0.83 and the standard deviation amounted to 0.025 .

Exemplary transient coefficient of friction measurement data of clads are given in Fig. 2(a). It became apparent, that the friction coefficients were shifted to lower values compared to the results of the reference tests. Furthermore, it was revealed, that the properties of the clads were considerably influenced by the substrate material. Clads on steel substrate showed higher friction coefficients compared to the cladded tracks on aluminum bronze substrate. An average of the friction coefficient was calculated for every variation of the clads. The results are summarized in Fig. 2(b). The friction coefficients of clads on steel substrate amounted to a range from 0.58 to 0.78 . In contrast, the deposited tracks on aluminum bronze substrate showed a lower friction coefficient that was only half of the friction coefficients in the case of steel substrate. Values of friction coefficients from 0.23 to 0.28 were determined. Indeed, through variation of the cladding speed, powder particle size and applying a postprocess laser remelting treatment, the tribological behaviour of the surfaces could neither significantly be varied nor improved.

Based on the finding that the friction coefficient was particularly influenced by the substrate material, the approach was developed to manufacture the entire deep drawing tool out of aluminum bronze by the laser deposition process. Hence, the tribological behaviour of the tool surface would be independent of the substrate. On the basis of the tribological findings, the friction coefficient would be approximately 0.25 against 1.4301 in dry sliding.

\section{Additive manufacturing of a deep drawing tool}

\subsection{Additive manufacturing process}

The near-net-shape geometries of the blank holder, the drawing die and the punch on aluminum bronze substrate were generated by direct laser deposition. After the additive manufacturing process the geometries were milled to receive the defined dimensions. In Fig. 3 the laser generated punch, blank holder and drawing ring are illustrated. For the additive manufacturing process a laser power of $2.5 \mathrm{~kW}$ was used. The powder feed rate amounted to $20 \mathrm{~g} / \mathrm{min}$ and the depositing speed was $0.5 \mathrm{~m} / \mathrm{min}$. For adjusting the layers in vertical direction, an increment of $0.75 \mathrm{~mm}$ was used and the overlapping 

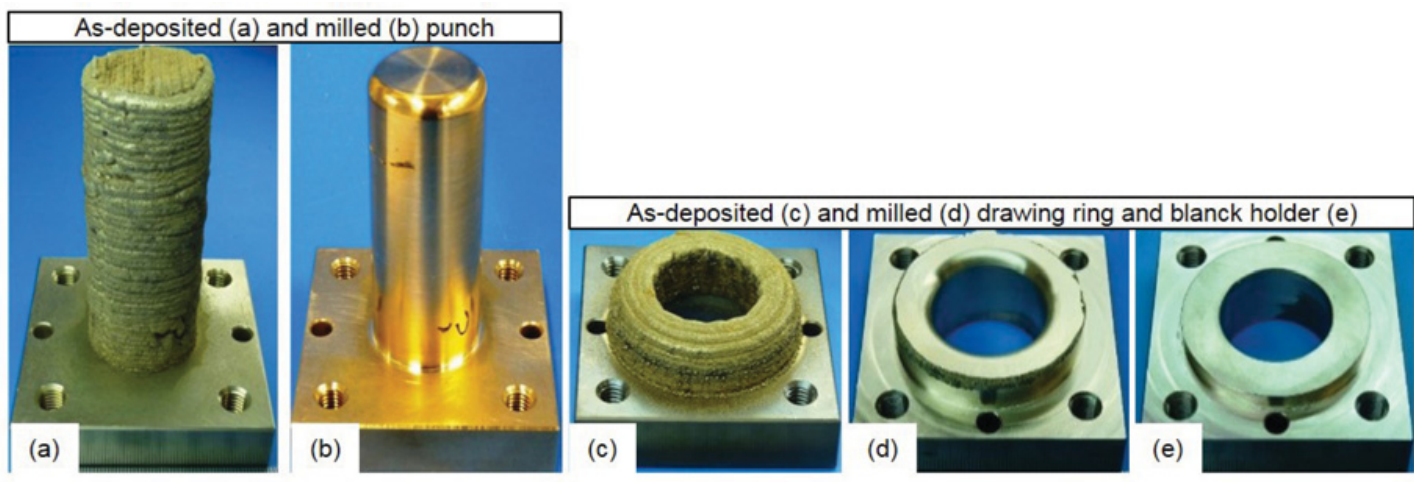

Freiße 2015

BIAS ID 150398

Figure 3. Additive manufactured and milled deep drawing tool.

increment in horizontal direction amounted to $2 \mathrm{~mm}$. The catchment efficiency of the powder material was around $70 \%$. The drawing die and the blank holder were generated by applying horizontal and vertical arranged rings. The deposition strategy for the punch was chosen to realise an inner area by linear tracks and the outer boundary by depositing a ring. The height of the punch amounted to $70 \mathrm{~mm}$ and the diameter was $30 \mathrm{~mm}$.

The punch was cut in the center to assess the quality on the metallurgical cross section regarding imperfections and hardness distribution. Smaller pores with diameters up to $50 \mu \mathrm{m}$ were observed. No cracks were detected. Within the hardness measurements, an average value of 186.6 HV0.5 with standard deviation of 9.8 HV0.5 was determined. The hardness was homogeneously distributed in the punch.

\subsection{Dry metal forming of circular cups}

All process data, geometries and acronyms of the deep drawing experiments are given in Table 1.

Previously, the blank holder force (1) and the punch force (2) were calculated by [9]:

$$
\begin{aligned}
\mathrm{F}_{\mathrm{BH}} & =\mathrm{p}_{\mathrm{BH}} * \mathrm{~A}_{\mathrm{BH}} \\
\mathrm{F}_{\mathrm{P}} & =\pi *\left(\mathrm{~d}_{1}+\mathrm{s}\right) * \mathrm{~s} * \mathrm{R}_{\mathrm{m}} * 1.2 *(\beta-1) /\left(\beta_{\max }-1\right) .
\end{aligned}
$$

For the forming process, the parts of the deep drawing tool were installed in a deep drawing guiding device. The motion for the deep drawing process was applied by a $250 \mathrm{kN}$ Zwick Roell Z250 compression tension testing machine. The blankholder force was applied by four helical compression springs and was set by adjusting the suspension travel. For the deep drawing test, the punch travel and the forming speed were kept constant and the required punch force was measured.

For examining the optimal blank holder force, lubricated deep drawing experiments were carried out by variation of the blank holder force from $1.8 \mathrm{kN}$ to $2.9 \mathrm{kN}$. The results are shown in Fig. 4 . The lubricant Wisura AK3080 was used. It was noted that using the calculated blankholder force of $2.3 \mathrm{kN}$ wrinkles were visible. By increasing the force to $2.9 \mathrm{kN}$ the wrinkle formation could be avoided and no bottom fractures were observed. The higher blank holder force led to an increase of the punch force. Using a blank holder force of $1.8 \mathrm{kN}$, a punch force of $21.4 \mathrm{kN}$ was necessary and within using a higher blank holder force of $2.9 \mathrm{kN}$ a punch force of $25.4 \mathrm{kN}$ had to be applied. 
Table 1. Parameters and geometries of the deep drawing process.

\begin{tabular}{|c|c|c|c|c|}
\hline Parameter & Symbols & Value & Unit & \\
\hline Punch diameter & $\mathrm{d}_{1}$ & 30 & $\mathrm{~mm}$ & \multirow{9}{*}{ 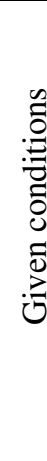 } \\
\hline Hight of the cup & $\mathrm{h}$ & 15 & $\mathrm{~mm}$ & \\
\hline Sheet thickness & $\mathrm{s}$ & 0.5 & $\mathrm{~mm}$ & \\
\hline Punch radius & $\mathrm{r}_{\mathrm{P}}$ & 4 & $\mathrm{~mm}$ & \\
\hline Drawring radius & $r_{D R}$ & 4 & $\mathrm{~mm}$ & \\
\hline Tensile strength of the sheet & $\mathrm{R}_{\mathrm{m}}$ & 750 & $\mathrm{~N} / \mathrm{mm}^{2}$ & \\
\hline Maximum drawing ration & $\beta_{\max }$ & 2 & l & \\
\hline Blankholder pressure & $\mathrm{p}_{\mathrm{BH}}$ & 2.5 & $\mathrm{~N} / \mathrm{mm}^{2}$ & \\
\hline Forming speed & $\mathrm{v}$ & 10 & $\mathrm{~mm} / \mathrm{s}$ & \\
\hline Blank diameter & $\mathrm{d}_{0}$ & 52 & $\mathrm{~mm}$ & \multirow{8}{*}{$\frac{\frac{d}{\tilde{J}}}{\frac{0}{0}}$} \\
\hline Drawring diameter & $\mathrm{d}_{\mathrm{DR}}$ & 31.4 & $\mathrm{~mm}$ & \\
\hline Blankholder diameter & $\mathrm{d}_{\mathrm{BH}}$ & 31 & $\mathrm{~mm}$ & \\
\hline Blank holder area & $\mathrm{A}_{\mathrm{BH}}$ & 905 & $\mathrm{~mm}^{2}$ & \\
\hline Drawing clearance & $\mathrm{w}$ & 0.70 & $\mathrm{~mm}$ & \\
\hline Drawing ration & $\beta$ & 1.73 & l & \\
\hline Punch force & $\mathrm{F}_{\mathrm{P}}$ & 39 & $\mathrm{kN}$ & \\
\hline Blankholder force & $\mathrm{F}_{\mathrm{BH}}$ & 2.3 & $\mathrm{kN}$ & \\
\hline
\end{tabular}

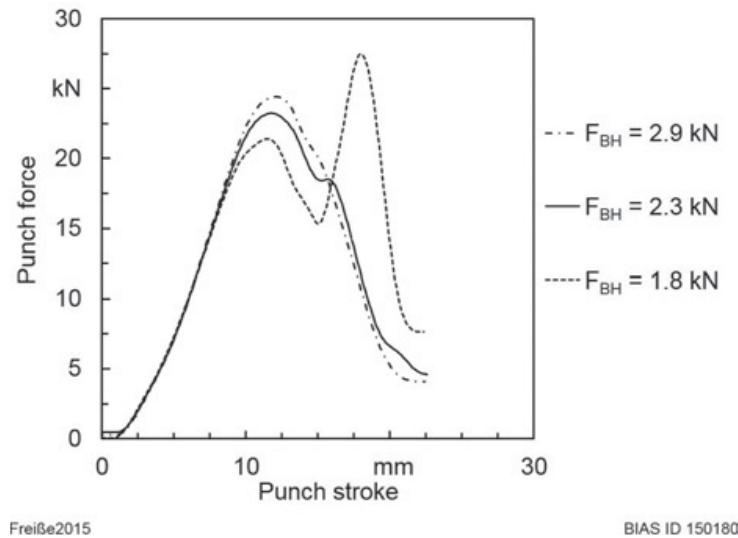

Figure 4. Results of the deep drawing tests.

In the next step, the deep drawing tests were carried out with and without lubrication using blankholder force of $2.9 \mathrm{kN}$. Figure 5 shows the results of the deep drawing test with and without lubricant and an example of a dry formed cup.

All formed cups were without any wrinkles and cup base fractures. The transient measurement data of all forming processes showed a homogeneously shape. Particularly, the average of the maximum punch force was just about 5\% higher when the forming process was carried out without lubrication compared to the lubricated forming process. The standard deviation was less than $1 \mathrm{kN}$. 


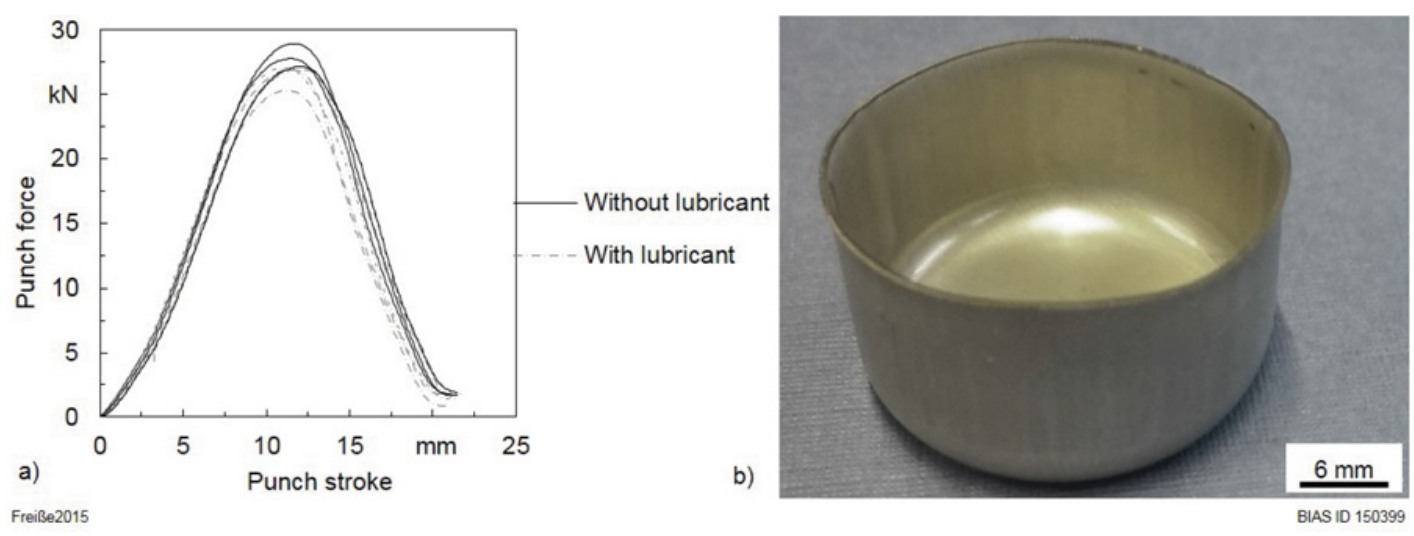

Figure 5. Results of the deep drawing test with and without lubricant (a) and example of a dry formed cup (b).

\section{Summary}

The tribological investigations of laser clads in a dry oscillating ball-on-plate test against high alloy steel 1.4301 showed that the friction coefficient was mainly influenced by the substrate material. In the case of steel substrate, a higher friction coefficient was measured. Using aluminum bronze substrate for the claddings, a lower friction coefficient of around 0.25 was measured. Hence, the idea was developed to generate the whole deep drawing tool out of aluminum bronze using the cladding process by additive manufacturing process. The generated tool was used to form circular cups out of 1.4301. The forming process was carried out with and without lubrication. The average of the maximum punch force was just about $5 \%$ higher in the case of lubricant-free forming.

This work was supported by Deutsche Forschungsgemeinschaft (DFG) within priority programme 1676 (Se1435/2-1).

\section{References}

[1] F. Vollertsen, F. Schmidt, Int. J. Prec. Eng. Manuf. Green Tech., 1, 1 (2014)

[2] M. Schwander, D. Füller, H. Köhler, F. Feuerhahn, M. Dias da Silva, F. Vollertsen, Prod. Eng. Res. Devel., 8, 5 (2014)

[3] D. Wulff, D. Yilkiran, U. Holländer, D. Lützenkirchen-Hecht, R. Wagner, S. Hübner, H.J. Maier, B.-A. Behrens, Dry Met. Forming OAJFMT, 1, 72-78 (2015)

[4] S. Kataoka, M. Murakawa, T. Aizawa, H. Ike, Surface and Coatings Technology 177-178, 582-590 (2004)

[5] A. Mousavi, A. Brosius, Dry Met. Forming OAJFMT, 1, 79-82 (2015)

[6] M. Rooij, Tribological aspects of unlubricated deepdrawing processes, Ph.D. Thesis, University of Twente (1998)

[7] M. Schmidt, R. Kolleck, A. Grimm, R. Veit, CIRP Annals - Man. Techn., 59 (2010)

[8] S. Nowotny, S. Scharek, E. Beyer, K.-H. Richter, J. Therm. Spray Technol., 16, 3 (2007)

[9] U. Fischer, R. Gomeringer, M. Heinzler, R. Kilgus, F. Näher, S. Oesterle, H. Paetzold, A. Stephan, Tabellenbuch Metall, 43, 321 (2005) 